\title{
BMJ Open Impact of CAre-related Regret Upon Sleep (ICARUS) cohort study: protocol of a 3-year multicentre, international, prospective cohort study of novice healthcare professionals
}

\author{
Boris Cheval, ${ }^{1,2}$ Stéphane Cullati, ${ }^{2,3}$ Jesper Pihl-Thingvad, ${ }^{4,5}$ Denis Mongin, ${ }^{1,2}$ \\ Martina Von Arx, ${ }^{3,6}$ Pierre Chopard, ${ }^{1,2}$ Delphine S Courvoisier ${ }^{1,2}$
}

To cite: Cheval B, Cullati S, Pihl-Thingvad J, et al. Impact of CAre-related Regret Upon Sleep (ICARUS) cohort study: protocol of a 3-year multicentre, international, prospective cohort study of novice healthcare professionals. BMJ Open 2018;0:e022172. doi:10.1136/ bmjopen-2018-022172

- Prepublication history for this paper is available online. To view these files, please visit the journal online (http://dx.doi. org/10.1136/bmjopen-2018022172).

Received 6 February 2018 Revised 9 February 2018 Accepted 13 February 2018

Check for updates

For numbered affiliations see end of article.

Correspondence to

Dr Boris Cheval;

boris.cheval@unige.ch

\section{ABSTRACT}

Introduction Healthcare professionals are particularly at risk of developing numerous physical and psychological health problems. The experiences of emotional burden associated with providing healthcare, notably care-related regret, have been associated with these health problems, but only using cross-sectional data so far. Evidence of a causal impact of regret has not been assessed. The Impact of CAre-related Regret Upon Sleep (ICARUS) study is the first prospective and international cohort study established to examine how newly practising healthcare professionals adapt to their challenging job by assessing the impact of care-related regret on sleep and job quitting.

Method and analysis The ICARUS cohort study will include newly practising healthcare professionals working in acute care hospitals and clinics recruited between May 2017 and November 2019. Data collection, which will begin as soon as the participant starts working with patients, will consist of a 1-year weekly assessment using a secure web survey. Follow-up data will be collected at 6, 12, 18 and 24 months after the end of the first year. We will collect detailed information on the experience of care-related regret (ie, highest regret intensity, accumulation of regrets and coping strategies related to regrets), sleep problems and job quitting. Moreover, quality of life, health status and burnout will be assessed during the follow-up. Several confounders factors, including sociodemographic characteristics, personality, night shifts and work environment characteristics, will be assessed.

Ethics and dissemination The study was approved by the Ethics Committee of Geneva Canton, Switzerland (CCER2016-02041), the Ethics Committee of London South Bank University (HSCSEP/17/06) and the University Research Ethics Committee of Bedfordshire (UREC106). Other study centres deemed local ethical approval unnecessary since the main ethics committee (Geneva) had already accepted the project. Results will be published in relevant scientific journals and be disseminated in international conferences. Fully anonymised data and questionnaires will be freely accessible to everyone (scientists and general public).

\section{Strengths and limitations of this study}

- The Impact of CAre-related Regret Upon Sleep (ICARUS) study is the first prospective and international cohort study of healthcare professionals examining the impact of care-related emotional burden, especially regret related to clinical decisions or actions, on sleep and job quitting.

- ICARUS population are newly practising healthcare professionals selected from a random sample of medical and nursing schools from the Frenchspeaking, English-speaking, German-speaking or Danish-speaking countries recruited between May 2017 and November 2019.

- The ICARUS study uses an intensive longitudinal data collection allowing to capture the real-time impact of care-related regret on sleep problems.

- The ICARUS study will collect rich data giving a detailed image of the development of critical coping skills necessary to healthcare professionals to provide good quality healthcare to patients while themselves remaining in good health.

- The ICARUS study is designed to minimise the inherent risks of bias associated with observational studies, but, as the participation is voluntary, a potential selection bias, due to attrition, cannot be excluded.

\section{INTRODUCTION}

Healthcare professionals are particularly at risk of numerous physical and psychological health problems, including back pain (eg, prevalence among home nurses: $19 \%),{ }^{1}$ sleep problems, ${ }^{2-5}$ depression (prevalence among medical doctors: $28.8 \%)^{6}$ and suicide (twofold increase in incidence among nurses and physicians). ${ }^{7}$ An increased rate of burnout from $45 \%$ to $54 \%$ between 2011 and 2014 was observed in Americans physicians, ${ }^{8}$ a trend similar in European countries, ${ }^{910}$ with newly practising physicians being particularly at risk. ${ }^{11-14}$ These outcomes often results 
in sleep problems, ${ }^{23}$ prolonged sick leave, ${ }^{15-17}$ job quitting $^{18-20}$ and have serious consequences on organisation and quality of patient care, ${ }^{21-26}$ and dramatic costs for the healthcare system. ${ }^{27-29}$

While the causes of these health problems involve multiple factors such as the clinical working environment, night shifts and job strain, ${ }^{30}$ one cause lies in the emotional burden associated with providing healthcare. ${ }^{532}$ Along with the emotional states that may affect healthcare providers' own health, such as moral distress, ${ }^{33}$ moral sensitivity, ${ }^{19}$ perception of inappropriate care provided to patients, ${ }^{34}$ loss of control over the care process $^{35}$ or involvement in medical errors, ${ }^{36}$ regret, a normal and frequent emotion, ${ }^{37}$ has recently increased attention. ${ }^{38}$ Regret is the emotion people feel when they think that the outcome would have been better if they had acted differently. ${ }^{39}$ For instance, if healthcare professionals believe that a patient's situation would have been better if they had behaved differently, they will experience regret. ${ }^{40}$ Of note, regret is associated both with negative outcomes, such as sleep problems, ${ }^{41}{ }^{42}$ but also with positive outcomes, such as enhanced learning. ${ }^{43} 44$ The regret regulation theory asserts that regret generate ameliorative cognitions. ${ }^{39} 45$ Indeed, regret allows making sense of the past, and facilitating approach and avoidance behaviours when appropriate, and preserving social harmony. ${ }^{46}$ In the clinical working environment, regrets occur frequently. Physicians and nurses perform countless clinical decisions and actions during their workday, in a context characterised by time pressure, information overload, increase in patient care complexity and uncertainty. ${ }^{47} 48$ Thus, many clinical events or situations may lead to feeling regret, whether there was a medical error or not. ${ }^{4950}$
Dealing with healthcare-related difficult events (eg, discovering that a patient is experiencing a lot of pain and should have received his medication half an hour earlier) or situations (eg, palliative care, paediatric and intensive cares) relies on coping strategies. One known classification of these strategies proposes two categories: problem-focused and emotion-focused. ${ }^{51}$ Problem-focused strategies aim at preventing similar situations in the future (eg, 'I will make a change in my schedule to visit my patient on time' or 'I will provide more pain medication in advance'). Emotion-focused strategies include suppression of regret-related thoughts (eg, 'It happened but let's not think about it'). In addition, social strategies (ie, seeking either an attentive ear or obtaining concrete support from others, such as a 5 min break) are either problem-focused or emotion-focused. How these strategies are used by physicians and nurses, and how effective they are in the context of providing healthcare, is still poorly understood.

Based on qualitative studies, ${ }^{49}$ we developed a framework to model the process of feeling regret, how these feelings and the associated coping can be characterised as exposure and the potential consequences of these exposures. Highest regret intensity, accumulation of regrets over time and coping strategies have a wide range of consequences on three levels (figure 1, outcomes).$^{38}$ First, regret influences physical and mental health at the individual level. The intensity of regret is associated with feelings of $\operatorname{loss}^{52}$ and with a wide range of physical and psychological symptoms. ${ }^{53}{ }^{54}$ Regret also disturbs sleep. ${ }^{42} 45$ Given that sleep loss may lead to attention deficits ${ }^{56}$ and thus to an increased risk of errors and regretted decisions, ${ }^{57}$ a vicious circle between errors, regrets and insomnia could emerge. ${ }^{58}$ Second,

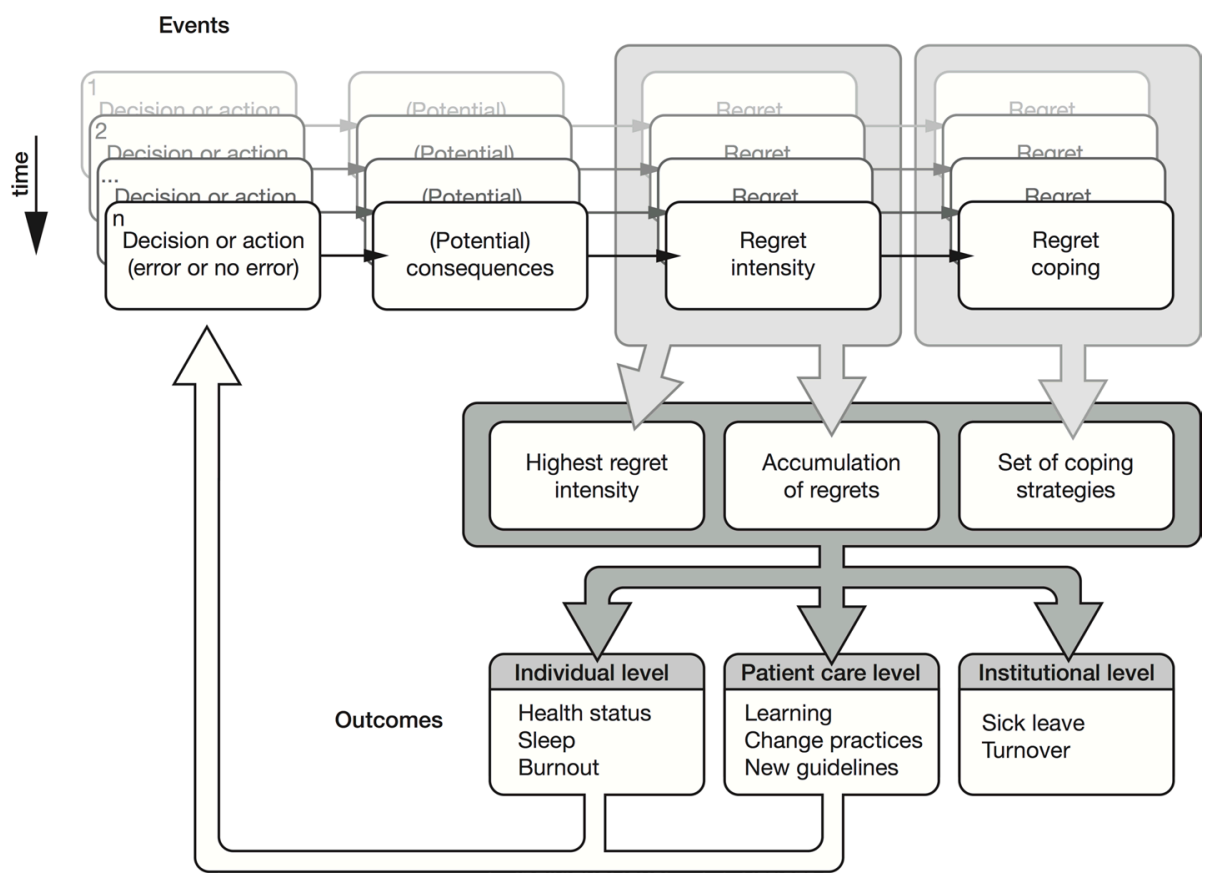

Figure 1 Theoretical relationships between regret, regret regulation and outcome variables. ${ }^{38}$ 
regret may influence safety decision ${ }^{59}$ and clinical decision-making, ${ }^{60-63}$ either at the individual level, through learning or clinical test ordering, ${ }^{6465}$ at the ward level, through changing practice in the ward (eg, rigorously applying identity bracelet checking), or at a more global level, through the diffusion of new guidelines. Finally, intense regrets decrease job satisfaction ${ }^{49}$ and may lead to more sick leave, ${ }^{66}$ and eventually to the decision to change jobs (figure 1).

Previous studies could not assess the causal impact of regret because of the cross-sectional nature of the designs. ${ }^{63}$ This limitation led to the initiation of the ICARUS cohort study in 2017 to examine how healthcare professionals adapt to their challenging job by assessing the impact of care-related emotional burden, especially regret related to clinical decisions or actions, on sleep and job quitting. Assessing causality in an observational study is very difficult. But at the minimum, it requires that the exposure occur before the outcome and that potential confounding variables were assessed and controlled. The Impact of CAre-related Regret Upon Sleep (ICARUS) cohort study attempts to meet these requirements by investigating regret and regret regulation as they occur in an ecological momentary assessment study, with a 1-week interval between each measure.

The project focuses on two primary outcomes: (1) sleep problems and (2) job quitting. Sleep problems are a very important issue for healthcare professionals because work characteristics (eg, shift work) already have a detrimental impact on sleep, ${ }^{52}$ especially among residents doctors. ${ }^{67}$ Furthermore, sleep problems increase the risk of medical error. ${ }^{26}{ }^{68}$ Career abandonment is also of particular interest since the costs of training doctors and nurses are considerable, ${ }^{69}$ that is, a loss of $>5 \%$ of the total annual operating budget. ${ }^{70}$

\section{METHOD AND DATA ANALYSIS \\ Study design}

The ICARUS cohort study is a prospective, longitudinal, multicentre and international study of newly practising healthcare professionals working in acute care hospitals and clinics. The ICARUS cohort study consists of 1-year weekly assessment using a secure web survey hosted by the University of Geneva, Switzerland. The rationale for this 1-week interval is that it should correspond to the time granularity necessary to assess the causal impact of regret on sleep, that is, regret should impact sleep for the next week and maybe a few weeks afterwards. Participants will be sent the survey on Monday afternoon and, if they do not answer, will receive up to two reminders per week, on Wednesday and Friday.

\section{Follow-up}

A questionnaire will be sent every 6 months in years 2-3 to obtain longer-term information on job quitting, as well as on quality of life, health status and burnout.

\section{Population}

Newly practising healthcare professionals working in acute care hospitals and clinics. We selected novice healthcare professionals because young age is a significant factor of turnover intentions. ${ }^{71}$ Moreover, young clinicians are at higher risk of regretted decisions and actions as they are still learning skills to do their job. Finally, a qualitative study ${ }^{49}$ suggested that many clinicians described intense experiences that dated back to their first years of clinical practice.

Between May 2017 and November 2019, students in nursing and medical schools will be invited to participate in the ICARUS study during their last year of training. Participants will be selected from a random sample of schools from the French-speaking, English-speaking, German-speaking and Danish-speaking countries. Specifically, before contacting participants, an email will be sent to the dean to ask for the permission to contact their students to invite them to take part in a study concerning the difficulties encountered by healthcare professionals when they start treating patients. As incentive, a small donation to a charity (Theodora foundation) of $0.5 \mathrm{CHF}$ for each completed survey will be made. To be included in the study, participants must be healthcare professionals, speak French, English, German or Danish and be willing to complete one short web survey per week for a maximum of 1 year and the four follow-up questionnaires. We exclude respondents who already provided healthcare in a professional capacity (ie, excluding internships). Data collection begins as soon as the participant starts working with patients.

\section{Sample size}

The estimates are based on expected number of career change among nurses (18\% over 3 years) ${ }^{15}$ We have five regret variables (number of regret over the past week, intensity of the most significant regret over the past week, three coping strategies). Current guidelines on sample size for predictive models require a minimum of 5 events (ie, turnover in this study) per predictor (ie, the five regret variables in this study), yielding a minimum of 25 necessary events. ${ }^{72}$ We expect a loss to follow-up of $10 \%$. Thus, we need a minimum of 153 nurses (25 events divided by 0.18 (incidence of turnover) times 1.1 (to compensate $10 \%$ loss to follow-up). An additional 47 nurses will be recruited to allow for a potential lower incidence of turnover and the potential inclusion of covariates in the model. For medical doctors, turnover rates are much lower and are also less documented. For this reason, sample size calculations are based on the sleep outcome, and more specifically on sleeping pill use. In a cross-sectional study, the regular use of sleeping pill was $14.3 \%$ among medical doctors younger than 30 years. ${ }^{42}$ Thus, the same sample size of 200 is necessary.

\section{Measures}

Table 1 summarises the measures of the ICARUS cohort study taken in year 1 , with which instrument and at which 
Table 1 Measures in year 1 of the Impact of CAre-related Regret Upon Sleep cohort study

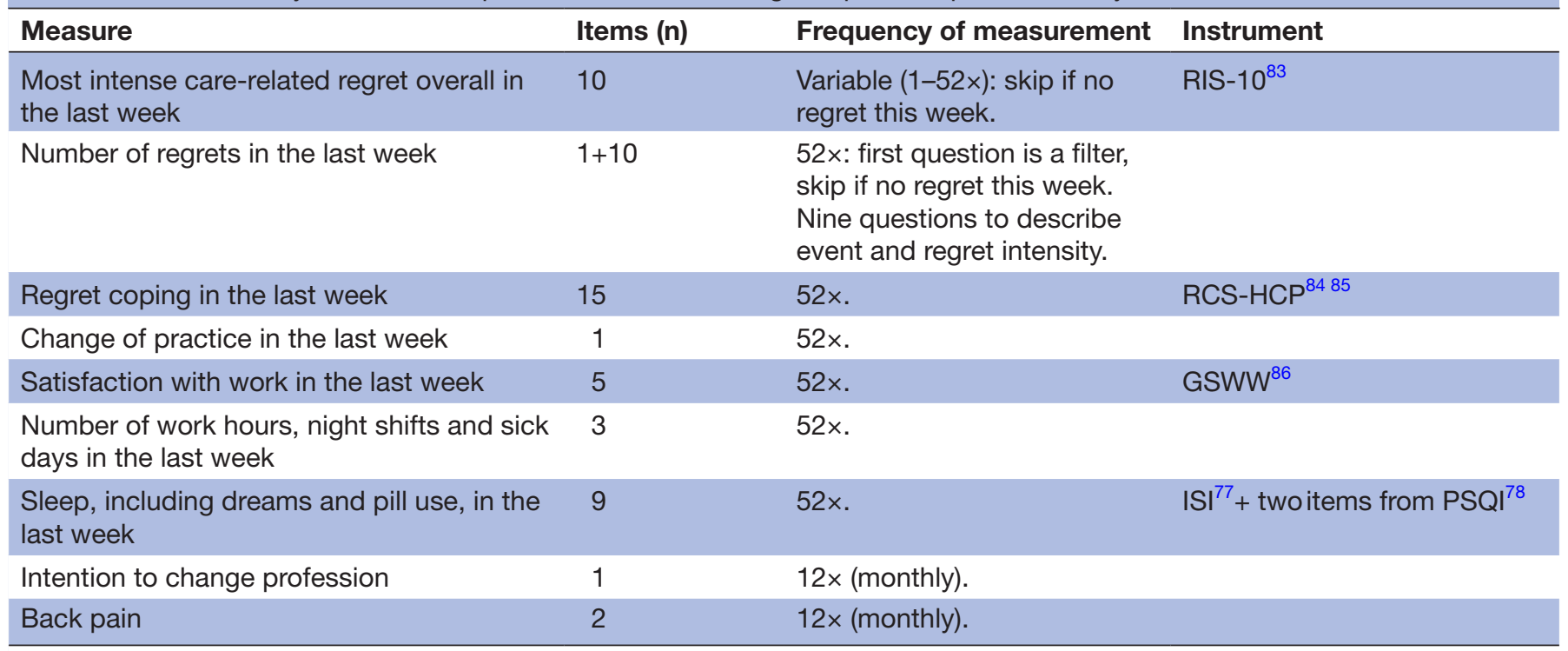

GSWW, Global Satisfaction with Work (Echelle de satisfaction globale au travail); ISI, insomnia severity index; PSQI, Pittsburgh Sleep Quality Index; RIS-10, Regret Intensity Scale; RCS-15, Regret Coping Scale.

frequency. Each weekly survey (65 questions) takes a maximum of $10 \mathrm{~min}$.

To allow for careful adjustment and thus reduce confounding bias, several confounders both at baseline and overtime are measured. In particular, we measure personality Ten-Item Personality Inventory (TIPI) ${ }^{73}$ and sociodemographic characteristics at baseline, but we also measure number of night shifts and work environment safety climate Safety Attitudes Questionnaire (SAQ). ${ }^{74}$

In addition, each 6 months over the remaining 2 years of the study, the survey will measure quality of life using EuroQol (EQ-5D) ${ }^{75}$ health status Short-Form health survey $(\mathrm{SF}-36),{ }^{76}$ sleep problems (ISI ${ }^{77}$ and two questions from the Pittsburgh Sleep Quality Index (PSQI) ${ }^{78}$ on dreams and pill use), burnout Professional Quality Of Life Scale (ProQOL) ${ }^{79}$ and professional status (ie, whether caregivers still work with patients). These surveys should take $<30 \mathrm{~min}$.

\section{Analysis}

Job quitting

We will use survival analysis to examine the impact of the five regret variables (frequency, highest intensity and three coping strategies) on job quitting. This analysis will be done separately by profession. Since regret is an exposure, which varies over time, several ways of characterising this exposure will be tried. In addition, we will also examine the possibility to characterise individuals as having efficient versus inefficient coping skills using cluster analysis. We will then determine if people with inefficient coping are more at risk of job quitting or sleep problems.

\section{Sleep problems}

In this analysis, regret intensity will influence regret coping, and both should have a causal impact on sleep. At the same time, sleep problems are known to worsen regret regulation. Thus, analysis will require careful statistical modelling of circular causality. We will examine the circular causality between regrets and sleep problems in a series of cross-lagged Bayesian models. In these models, we will estimate the cross-lagged association of regret in a given week with sleep problems of the following week, simultaneously with the crosslagged association of sleep problems in a given week with regret of the next week and with the autoregressions of both sleep problems and regret. ${ }^{80}$ All analyses will be performed with $\mathrm{R}$ using lme4, lmerTest, CODA, r2winbugs packages and WinBUGS. ${ }^{80} 81$

\section{Ethics and dissemination}

Other study centres deemed local ethical approval unnecessary since the main ethics committee (Geneva) had already accepted the project. All participants will give an informed consent to participate in the study.

Results will be published in relevant scientific journal and be disseminated in international conferences. In line with the Swiss National Science Foundation guidelines, data in a fully anonymised version and questionnaires will be freely accessible to everyone (scientists and general public).

\section{DISCUSSION}

The ICARUS cohort study is a prospective, multicentre, international and longitudinal study of newly practising healthcare professionals. So far, the ICARUS study is the only prospective cohort study examining the impact of 
care-related regrets on health-related outcomes. The uses of an intensive longitudinal data collection will help to capture the real-time impact of regret on sleep problems. The rich data will also give a detailed image of the development of critical coping skills necessary to provide healthcare while remaining in good health.

The ICARUS cohort study is designed to minimise the inherent risks of bias associated with observational studies. To minimise forgetting and memory biases, data will be collected at short time lag intervals (each week) using an internet-based survey. Another advantage of this method of data collection is that subjects feel more comfortable reporting higher level of distress and feelings such as guilt, shame, humiliation or anger when they are using automated systems. ${ }^{82}$ As the study relies on voluntary participation, the potential bias of selection cannot be excluded. However, because we are interested in changes within a given individuals, this selection bias will be unlikely to explain the pattern of results. Furthermore, the use of self-reported questionnaires for regret and sleep problems may artificially inflate the association between them due to self-reporting bias. Yet, the sleep scales possess sound psychometric properties and good concurrent validity with polysomnography measures ${ }^{77}$ and the regret questionnaires have satisfactory construct validity. ${ }^{83} 84$ Finally, attrition is an issue in longitudinal studies, leading to a potential selection bias in the remaining sample. Yet, the planned analyses will allow to include all the healthcare professionals in the models, even those who only answer once, thereby limiting this bias.

\section{Author affiliations}

${ }^{1}$ Quality of Care Service, University Hospital of Geneva, Geneva, Switzerland ${ }^{2}$ Department of General Internal Medicine, Rehabilitation and Geriatrics, University of Geneva, Geneva, Switzerland

${ }^{3}$ Swiss NCCR "Lives: Overcoming Vulnerability: Life Course Perspectives", University of Geneva, Geneva, Denmark

${ }^{4}$ Department of Occupational and Environmental Medicine, Odense University Hospital, Odense, Denmark

${ }^{5}$ National Center of Psychotraumatology, University of Southern Denmark, Odense, Denmark

${ }^{6}$ Institute of Demography and Socioeconomics, University of Geneva, Geneva, Switzerland

Contributors DSC conceived the study and is the principal investigator. BC, SC, JPT, DM, MVA and PC contributed to the conception of the study. All authors approved the version to be published and are responsible for its accuracy.

Funding The ICARUS cohort study was supported by the Swiss National Science Foundation (grant number 166010).

Competing interests None declared.

Patient consent Obtained.

Ethics approval The study was approved by the Ethics Committee of Geneva Canton, Switzerland (reference number: CCER2016-02041), the Ethics Committee of London South Bank University (reference number: HSCSEP/17/06) and the University Research Ethics Committee of Bedfordshire (reference number: UREC106).

Provenance and peer review Not commissioned; peer reviewed for ethical and funding approval prior to submission.

Data sharing statement In line with the Swiss National Science Foundation guidelines, fully anonymised data and questionnaires will be freely accessible to everyone (scientists and general public).
Open Access This is an Open Access article distributed in accordance with the Creative Commons Attribution Non Commercial (CC BY-NC 4.0) license, which permits others to distribute, remix, adapt, build upon this work non-commercially, and license their derivative works on different terms, provided the original work is properly cited and the use is non-commercial. See: http://creativecommons.org/ licenses/by-nc/4.0/

(c) Article author(s) (or their employer(s) unless otherwise stated in the text of the article) 2018. All rights reserved. No commercial use is permitted unless otherwise expressly granted.

\section{REFERENCES}

1. Dhaini SR, Zúñiga F, Ausserhofer D, et al. Care workers health in Swiss nursing homes and its association with psychosocial work environment: A cross-sectional study. Int J Nurs Stud 2016;53:105-15.

2. Bjorvatn B, Dale S, Hogstad-Erikstein R, et al. Self-reported sleep and health among Norwegian hospital nurses in intensive care units. Nurs Crit Care 2012;17:180-8.

3. Vela-Bueno A, Moreno-Jiménez B, Rodríguez-Muñoz A, et al. Insomnia and sleep quality among primary care physicians with low and high burnout levels. J Psychosom Res 2008;64:435-42.

4. Owens JA. Sleep loss and fatigue in healthcare professionals. J Perinat Neonatal Nurs 2007;21:92-100.

5. Hansen CD, Rasmussen K, Kyed M, et al. Physical and psychosocial work environment factors and their association with health outcomes in Danish ambulance personnel - a cross-sectional study. BMC Public Health 2012;12:534.

6. Mata DA, Ramos MA, Bansal N, et al. Prevalence of Depression and Depressive Symptoms Among Resident Physicians: A Systematic Review and Meta-analysis. JAMA 2015;314:2373-83.

7. Hawton K, Agerbo E, Simkin S, et al. Risk of suicide in medical and related occupational groups: a national study based on Danish case population-based registers. J Affect Disord 2011;134:320-6.

8. Shanafelt TD, Hasan O, Dyrbye LN, et al. Changes in Burnout and Satisfaction With Work-Life Balance in Physicians and the General US Working Population Between 2011 and 2014. Mayo Clin Proc 2015;90:1600-13.

9. Arigoni F, Bovier PA, Sappino AP. Trend of burnout among Swiss doctors. Swiss Med Wkly 2010;140:w13070.

10. Pedersen AF, Andersen CM, Olesen F, et al. Risk of Burnout in Danish GPs and Exploration of Factors Associated with Development of Burnout: A Two-Wave Panel Study. Int J Family Med 2013;2013:1-8.

11. Dyrbye LN, West CP, Satele D, et al. Burnout among U.S. medical students, residents, and early career physicians relative to the general U.S. population. Acad Med 2014;89:443-51.

12. Dyrbye $L$, Shanafelt T. A narrative review on burnout experienced by medical students and residents. Med Educ 2016;50:132-49.

13. Ishak WW, Lederer S, Mandili C, et al. Burnout during residency training: a literature review. J Grad Med Educ 2009;1:236-42.

14. Thomas NK. Resident burnout. JAMA 2004;292:2880-9.

15. Josephson $M$, Lindberg $P$, Voss $M$, et al. The same factors influence job turnover and long spells of sick leave--a 3-year follow-up of Swedish nurses. Eur J Public Health 2008;18:380-5.

16. Dewa CS, Loong D, Bonato S, et al. How does burnout affect physician productivity? A systematic literature review. BMC Health Serv Res 2014;14:325.

17. Sawatzky JA, Enns CL. Exploring the key predictors of retention in emergency nurses. J Nurs Manag 2012;20:696-707.

18. Hayes LJ, O'Brien-Pallas L, Duffield C, et al. Nurse turnover: a literature review. Int J Nurs Stud 2006;43:237-63.

19. Schluter J, Winch S, Holzhauser K, et al. Nurses' moral sensitivity and hospital ethical climate: a literature review. Nurs Ethics 2008;15:304-21.

20. Addor V, Jeannin A, Schwendimann R, et al. Career paths of 1988 and 1998 nurse graduates in Switzerland: nurses at work pilot study. J Nurs Manag 2017;25:318-25.

21. Ma C, Shang J, Bott MJ. Linking Unit Collaboration and Nursing Leadership to Nurse Outcomes and Quality of Care. J Nurs Adm 2015;45:435-42.

22. de Jong MA, Nieuwenhuijsen K, Sluiter JK. Common mental disorders related to incidents and behaviour in physicians. Occup Med 2016;66:506-13.

23. Shanafelt T, Dyrbye L. Oncologist burnout: causes, consequences, and responses. J Clin Oncol 2012;30:1235-41.

24. Ratanawongsa N, Roter D, Beach MC, et al. Physician burnout and patient-physician communication during primary care encounters. $J$ Gen Intern Med 2008;23:1581-8. 
25. Letvak S, Ruhm C, Lane S. The impact of nurses' health on productivity and quality of care. J Nurs Adm 2011;41:162-7.

26. Patterson PD, Weaver MD, Frank RC, et al. Association between poor sleep, fatigue, and safety outcomes in emergency medical services providers. Prehosp Emerg Care 2012;16:86-97.

27. Letvak SA, Ruhm CJ, Gupta SN. Nurses' presenteeism and its effects on self-reported quality of care and costs. Am J Nurs 2012;112:30-8.

28. Geiger-Brown J, Rogers VE, Trinkoff AM, et al. Sleep, sleepiness, fatigue, and performance of 12-hour-shift nurses. Chronobiol Int 2012;29:211-9.

29. Philibert I. Sleep loss and performance in residents and nonphysicians: a meta-analytic examination. Sleep 2005;28:1392-402.

30. Eriksen W, Bjorvatn B, Bruusgaard D, et al. Work factors as predictors of poor sleep in nurses' aides. Int Arch Occup Environ Health 2008;81:301-10.

31. Portela LF, Kröning Luna C, Rotenberg L, et al. Job strain and self-reported insomnia symptoms among nurses: what about the influence of emotional demands and social support? Biomed Res Int 2015;2015:1-8

32. Lamiani G, Dordoni P, Argentero P. Value congruence and depressive symptoms among critical care clinicians: the mediating role of moral distress. Stress Health 2018;34:1-8.

33. Huffman DM, Rittenmeyer L. How professional nurses working in hospital environments experience moral distress: a systematic review. Crit Care Nurs Clin North Am 2012;24:91-100.

34. Piers RD, Azoulay E, Ricou B, et al. Perceptions of appropriateness of care among European and Israeli intensive care unit nurses and physicians. JAMA 2011;306:2694-703.

35. Shapiro J, Astin J, Shapiro SL, et al. Coping with loss of control in the practice of medicine. Fam Syst Health 2011;29:15-28.

36. Sirriyeh R, Lawton R, Gardner P, et al. Coping with medical error: a systematic review of papers to assess the effects of involvement in medical errors on healthcare professionals' psychological well-being. Qual Saf Health Care 2010;19:e43.

37. Shimanoff SB. Commonly named emotions in everyday conversations. Percept Mot Skills 1984;58:514-14.

38. Courvoisier D, Merglen A, Agoritsas T. Experiencing regrets in clinical practice. Lancet 2013;382:1553-4.

39. Zeelenberg M, Pieters R. A Theory of Regret Regulation 1.0. Journal of Consumer Psychology 2007;17:3-18.

40. Wadkins TA, Regret MRL. Keith KD, ed. The Encyclopedia of CrossCultural Psychology. New York: Wiley, 2013.

41. Schmidt RE, Van der Linden M. Feeling too regretful to fall asleep: experimental activation of regret delays sleep onset. Cognit Ther Res 2013;37:872-80.

42. Schmidt RE, Cullati S, Mostofsky E, et al. Healthcare-related regret among nurses and physicians is associated with self-rated insomnia severity: a cross-sectional study. PLoS One 2015;10:e0139770.

43. Marchiori D, Warglien M. Predicting human interactive learning by regret-driven neural networks. Science 2008;319:1111-3.

44. O'Connor E, McCormack T, Feeney A. Do children who experience regret make better decisions? A developmental study of the behavioral consequences of regret. Child Dev 2014;85:1995-2010.

45. Morrison M, Roese NJ. Regrets of the typical American: findings from a nationally representative sample. Soc Psychol Pers Sci $2011 ; 2: 576-83$

46. Saffrey C, Summerville A, Roese NJ. Praise for regret: people value regret above other negative emotions. Motiv Emot 2008;32:46-54.

47. Wenger $\mathrm{N}$, Méan M, Castioni J, et al. Allocation of internal medicine resident time in a Swiss Hospital: a time and motion study of day and evening shifts allocation of internal medicine resident time in a Swiss Hospital. Ann Intern Med 2017;166:579-86.

48. Teno JM, Gozalo PL, Bynum JP, et al. Change in end-of-life care for Medicare beneficiaries: site of death, place of care, and health care transitions in 2000, 2005, and 2009. JAMA 2013;309:470-7.

49. Courvoisier DS, Agoritsas T, Perneger TV, et al. Regrets associated with providing healthcare: qualitative study of experiences of hospital-based physicians and nurses. PLoS One 2011;6:e23138.

50. Laue J, Melbye H, Halvorsen PA, et al. How do general practitioners implement decision-making regarding COPD patients with exacerbations? An international focus group study. Int J Chron Obstruct Pulmon Dis 2016;11:3109-19.

51. Carver CS, Connor-Smith J. Personality and coping. Annu Rev Psychol 2010;61:679-704

52. Akiyama A, Numata K, Mikami H. Importance of end-of-life support to minimize caregiver's regret during bereavement of the elderly for better subsequent adaptation to bereavement. Arch Gerontol Geriatr 2010:50:175-8.
53. Roese NJ, Epstude K, Fessel F, et al. Repetitive regret, depression, and anxiety: findings from a nationally representative survey. J Soc Clin Psychol 2009;28:671-88.

54. Wrosch C, Bauer I, Scheier MF. Regret and quality of life across the adult life span: the influence of disengagement and available future goals. Psychol Aging 2005;20:657-70.

55. Schmidt RE, Van der Linden $M$. The aftermath of rash action: sleep-interfering counterfactual thoughts and emotions. Emotion 2009:9:549-53.

56. Varkevisser M, Kerkhof GA. Chronic insomnia and performance in a 24-h constant routine study. J Sleep Res 2005;14:49-59.

57. Scott LD, Arslanian-Engoren C, Engoren MC. Association of sleep and fatigue with decision regret among critical care nurses. Am J Crit Care 2014;23:13-23.

58. Zohar D, Tzischinsky O, Epstein R, et al. The effects of sleep loss on medical residents' emotional reactions to work events: a cognitiveenergy model. Sleep 2005;28:47-54.

59. Koch EJ. How does anticipated regret influence health and safety decisions? A literature review. Basic Appl Soc Psych 2014;36:397-412.

60. Stiegler MP, Tung A. Cognitive processes in anesthesiology decision making. Anesthesiology 2014;120:204-17.

61. Djulbegovic M, Beckstead J, Elqayam S, et al. Thinking styles and regret in physicians. PLoS One 2015;10:e0134038.

62. Le Minor M, Alpérovitch A, Knill-Jones RP. Applying decision theory to medical decision-making--concept of regret and error of diagnosis. Methods Inf Med 1982;21:3-8.

63. Wilson A, Ronnekleiv-Kelly SM, Pawlik TM. Regret in surgical decision making: a systematic review of patient and physician perspectives. World J Surg 2017;41:1454-65.

64. Sorum PC, Mullet E, Shim J, et al. Avoidance of anticipated regret: the ordering of prostate-specific antigen tests. Med Decis Making 2004;24:149-59.

65. Jessen K, Søndergaard J, Larsen PV, et al. Danish general practitioners' use of prostate-specific antigen in opportunistic screening for prostate cancer: a survey comprising 174 GPs. Int J Family Med 2013;2013:1-6.

66. Cullati S, Cheval B, Schmidt RE, et al. Self-rated health and sick leave among nurses and physicians: the role of regret and coping strategies in difficult care-related situations. Front Psychol 2017;8:623.

67. Mansukhani MP, Kolla BP, Surani S, et al. Sleep deprivation in resident physicians, work hour limitations, and related outcomes: a systematic review of the literature. Postgrad Med 2012;124:241-9.

68. Majekodunmi A, Landrigan CP. The effect of physician sleep deprivation on patient safety in perinatal-neonatal medicine. Am J Perinatol 2012;29:43-8.

69. Mukamel DB, Spector WD, Limcangco R, et al. The costs of turnover in nursing homes. Med Care 2009;47:1039-45.

70. Waldman JD, Kelly F, Arora S, et al. The shocking cost of turnover in health care. Health Care Manage Rev 2004;29:2-7.

71. Tw N, Feldman DC. Re-examining the relationship between age and voluntary turnover. J Vocat Behav 2009;74:283-94.

72. Courvoisier DS, Combescure C, Agoritsas T, et al. Performance of logistic regression modeling: beyond the number of events per variable, the role of data structure. J Clin Epidemiol 2011;64:993-1000.

73. Gosling SD, Rentfrow PJ, Swann WB. A very brief measure of the Big-Five personality domains. J Res Pers 2003;37:504-28.

74. Sexton JB, Helmreich RL, Neilands TB, et al. The Safety Attitudes Questionnaire: psychometric properties, benchmarking data, and emerging research. BMC Health Serv Res 2006;6:44.

75. Perneger TV, Combescure C, Courvoisier DS. General population reference values for the French version of the EuroQol EQ-5D health utility instrument. Value Health 2010;13:631-5.

76. Ware JE, Sherbourne CD. The MOS 36-item short-form health survey (SF-36). I. Conceptual framework and item selection. Med Care 1992;30:473-83.

77. Morin CM, Belleville G, Bélanger L, et al. The Insomnia Severity Index: psychometric indicators to detect insomnia cases and evaluate treatment response. Sleep 2011;34:601-8.

78. Buysse DJ, Reynolds CF, Monk TH, et al. The Pittsburgh Sleep Quality Index: a new instrument for psychiatric practice and research. Psychiatry Res 1989;28:193-213.

79. Stamm BH. The concise ProQOL manual. Pocatello, ID: proqol. org, 2010.

80. Schuurman NK, Ferrer E, de Boer-Sonnenschein M, et al. How to compare cross-lagged associations in a multilevel autoregressive model. Psychol Methods 2016;21:206-21. 
81. Lunn DJ, Thomas A, Best N, et al. WinBUGS-a Bayesian modelling framework: concepts, structure, and extensibility. Stat Comput 2000;10:325-37.

82. Sikorskii A, Given CW, Given B, et al. Differential symptom reporting by mode of administration of the assessment: automated voice response system versus a live telephone interview. Med Care 2009;47:866-74.

83. Courvoisier DS, Cullati S, Haller CS, et al. Validation of a 10item care-related regret intensity scale (RIS-10) for health care professionals. Med Care 2013;51:285-91.
84. Courvoisier DS, Cullati S, Ouchi R, et al. Validation of a 15-item carerelated regret coping scale for health-care professionals (RCS-HCP). J Occup Health 2014;56:430-43.

85. Pihl-Thingvad J, Wichmann Jacobsen C, Brandt LPA, et al. The Regret Coping Scale for Health-Care Professionals (RCS-HCP): Validation on Danish social educators. Work. In Press.

86. Blais MR, Brière NM. L'inventaire des motivations au travail de Blais. Rev Que Psychol 1993;14:185-215. 